University of Nebraska - Lincoln

DigitalCommons@University of Nebraska - Lincoln

September 1981

\title{
A test of macroevolutionary problems with neontological data
}

Cliff A. Lemen

University of Nebraska-Lincoln, clemen2@unl.edu

Patricia W. Freeman

University of Nebraska-Lincoln, pfreeman1@unl.edu

Follow this and additional works at: https://digitalcommons.unl.edu/natrespapers

Part of the Natural Resources and Conservation Commons

Lemen, Cliff A. and Freeman, Patricia W., "A test of macroevolutionary problems with neontological data" (1981). Papers in Natural Resources. 13.

https://digitalcommons.unl.edu/natrespapers/13

This Article is brought to you for free and open access by the Natural Resources, School of at DigitalCommons@University of Nebraska - Lincoln. It has been accepted for inclusion in Papers in Natural Resources by an authorized administrator of DigitalCommons@University of Nebraska - Lincoln. 


\title{
A test of macroevolutionary problems with neontological data
}

\author{
Cliff A. Lemen and Patricia W. Freeman
}

\begin{abstract}
Ricklefs (1980) suggested the use of neontological data to distinguish between puncuated equilibrium and gradualism as modes of evolution. This paper investigates his model and finds it contains oversimplifications that make any test difficult. We modify his model slightly and use it as a limited test of punctuated equilibrium by large morphological shifts at speciation. This test is applied to a data set of 110 species from two families of bats, the Emballonuridae and the Molossidae. We find no evidence of consistently large morphological shifts at the formation of subspecies, species or genera.
\end{abstract}

Cliff A. Lemen. Department of Zoology, Field Museum of Natural History, Chicago, Illinois 60605. Present address: School of Life Sciences, Manter Hall, University of Nebraska, Lincoln, Nebraska 68588

Patricia W. Freeman. Department of Zoology, Field Museum of Natural History, Chicago, Illinois 60605. Present address: University of Nebraska State Museum, Nebraska Hall, Lincoln, Nebraska 68588

Accepted: $\quad$ May 4, 1981

Introduction

When Eldredge and Gould (1972) proposed that the fossil record more closely resembles punctuated equilibrium than classical gradualism, they created a controversy. Most of the papers written on this subject use paleontological data (see Stanley 1980), but Ricklefs (1980) proposes that gradualism and punctuated equilibrium would result in basically different predictions of the morphological similarities of neontological taxa. The arguments of Ricklefs are largely mathematical, but they can be reduced to simple curves. His prediction of the distribution of nearest neighbor distances under the gradualism model and the extreme punctuated equilibrium model, are shown in Fig. 1.

The reasoning behind these curves hinges upon the assumed relationship between time since speciation from the nearest neighbor and morphological divergence from the nearest neighbor. Under either model of evolution, if speciation and extinctions are random through time, the frequency distribution of time since speciation for all species present at one point in time is a decreasing exponential function. The most common class of species is the youngest, the least common is the oldest. Strict gradualism predicts that the time since a species separated from its nearest neighbor will correlate strongly with the morphological divergence of that species from its nearest neighbor. Therefore, the most common class of species are morphologically very similar to their nearest neighbors, the least common class of species are morphologically very distinct from their nearest neighbors (Fig. 1A).

Punctuated equilibrium predicts that the time since speciation from the nearest neighbor has little to do with morphological divergence (given no further speciation events) because all morphological evolution takes place more or less instantaneously (Stanley 1980). The distribution of morphological divergences from nearest neighbors will take its shape from the degree of morphological divergence at speciation, modified by extinction. Ricklefs' model predicted the curve B in Fig. 1 as a likely shape for the morphological divergence curve under extreme punctuated equilibrium.

There is a dramatic qualitative difference in the shapes of the curves Ricklefs generated, and a test appears possible to distinguish between modes of evolution. Ricklefs pointed out that his model contained oversimplifications but felt that testing his predictions was necessary. We agree with him on both counts. Here we report our findings on the morphological structure of two families of bats, the Emballonuridae and 
Molossidae, and further, we investigate some of the problems in using Ricklefs' model as a test for gradualism or punctuated equilibrium. We find that some of the simplifying assumptions Ricklefs used to develop his model will so affect the qualitative differences in the curves in Fig. 1 that in some situations gradualism and punctuated equilibrium can produce the same distance to nearest neighbor curves.

\section{Materials and Methods}

Bats of the families Emballonuridae and Molossidae were used as the data base in this study. The comparisons among species and genera were made using one specimen of each of 110 species, representing 22 genera. Each specimen was measured for 42 morphological characters (see appendix for a list of these characters; illustrations are in Freeman, 1981).

The intra-populational data were obtained by measuring a series of specimens of one species and one sex caught at the same time and place. The species used and the sample sizes are Tadarida brasiliensis, $N=6$; Molossus molossus, $N=6$; and Taphozous nudiventris, $N=6$. The geographical variation within a species was obtained by using series of specimens from different localities. The species used and their sample sizes are $T$. brasiliensis, $N=4 ; M$. molossus, $N=5$; Saccopteryx bilineata, $N=6$. The within-population curve was formed by plotting all distances among the individuals in the series. The geographic variation curve was formed the same way. The distance to nearest interspecific neighbor within the genus consists of one distance for each species in genera with more than one species $(N=110)$. The same approach was used for the distance to nearest neighbor outside the genus $(N=110)$. This change in approach was necessary because while sample size among species is set at the number of species extant, the sample size for population samples or geographical variants is arbitrary. Increased sample size would produce smaller and smaller nearest neighbor distances and give no idea of the average or maximal dispersion of the sample. Plotting all distances allows comparison of these factors with between species distances.

Both size and shape analysis were used to determine distances. Because our measurements were so strongly affected by size we used

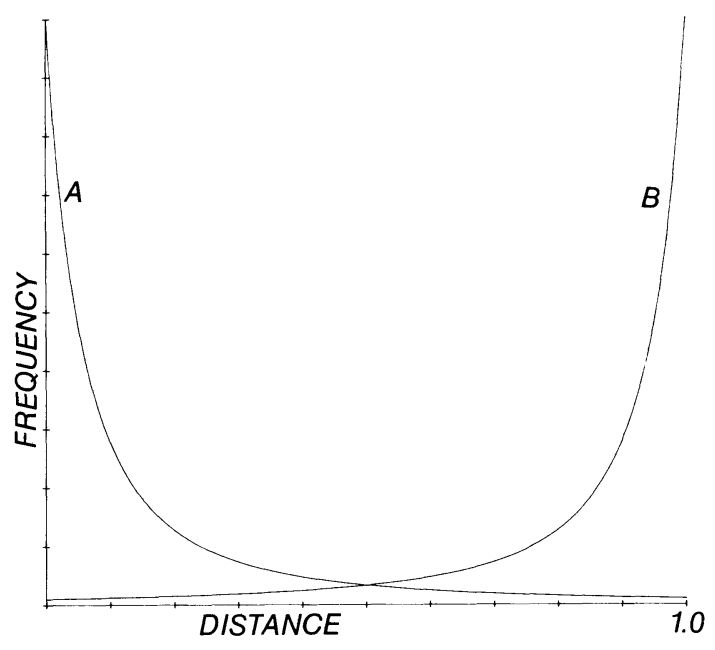

Figure 1. Two curves taken from Ricklefs (1980) and showing the relative frequency of distances to nearest neighbors. Curve $\mathrm{A}$ is the prediction of gradualism and curve $\mathrm{B}$ is the prediction of extreme punctuated equilibrium.

a shape method for graphic representation here. The size analysis method, not shown in this paper, produced similar results.

The shape analysis used is log sizeout described by Lemen (1981). The distance between two species in log sizeout space is:

$$
\sqrt{\left(\text { Distance }_{1,2}\right)^{2}-\left(\sqrt{N}\left(\bar{X}_{1}-\bar{X}_{2}\right)\right)^{2}}
$$

Where $N$ is the number of size related characters, $\bar{X}$ is the average of the log transformed size characters, and Distance is the distance between species in log transformed character space.

The results of shape analysis for the four taxonomic levels are shown in Fig. 2. The curve to be tested against Ricklefs' theoretical curves is Fig. 2C.

\section{Discussion}

Comparison of our interspecific distance to nearest neighbor curve (Fig. 2C) with the theoretical curves of Fig. 1 is unsatisfying. The curve generated from our data is unlike either predicted curve.

Going back to the mathematical models developed by Ricklefs, we looked for possible simplifications that while reasonable in a heuristic argument might make operational testing of the models difficult. We found several problems. First, with curve A in Fig. 1, the most common relationship between species is complete simi- 


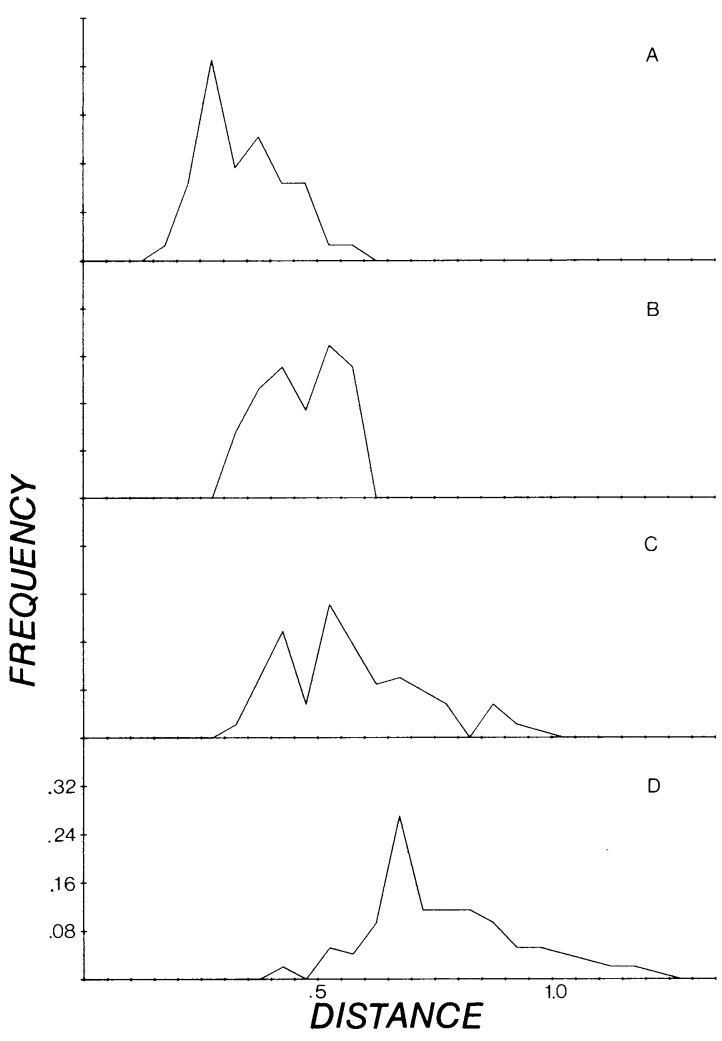

FIGURE 2. These curves, generated from two families of bats, represent the relative frequency of distances to neighbors for a taxonomic hierarchy. The curves shown are: A, distances within populations; B, distances between subspecies; $\mathrm{C}$, distances to nearest congener; and $\mathrm{D}$, distances to nearest non-congener.

larity. At some level this is necessarily erroneous as no two organisms are exactly alike. Perhaps with some types of data, when broad qualitative characters were used, complete agreement in characters is possible. But in a morphological study such as this, 0.000 distance in morphological or log sizeout space is essentially a mathematic impossibility. Therefore, the curve in Fig. 3A allows no two taxa to be exactly alike, and maintains most of the qualities of shape predicted by Ricklefs in Fig. 1A.

Second, in curve B in Fig. 1, the most common distance between nearest neighbors is 1.0. What is special about the distance 1.0? For Ricklefs (1980), 1.0 results from defining a maximal morphological divergence possible and constant morphological divergence at speciation. By allowing morphological divergence at speciation to vary, and abolishing the idea of maximal divergence, a curve more like the one in Fig. 3B would be predicted.

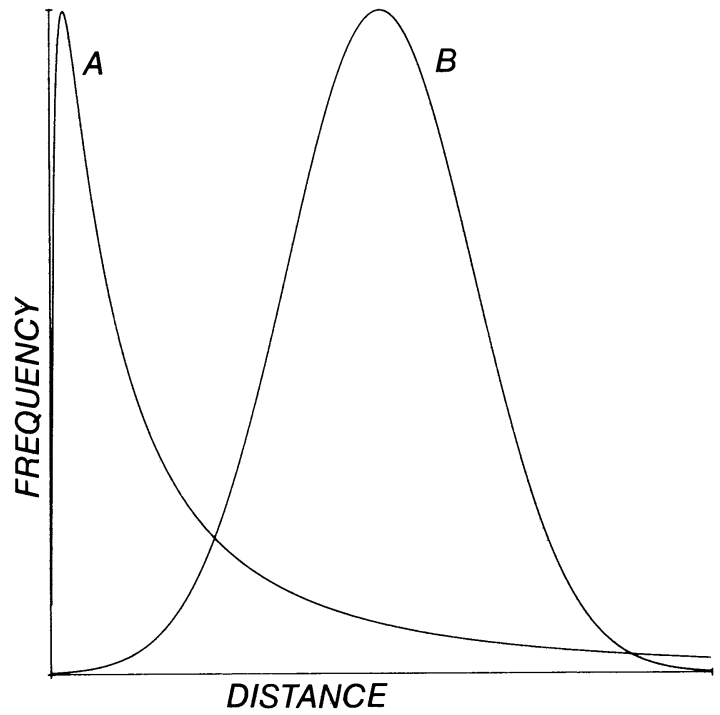

FIGURE 3. These two curves are our modifications of the curves found in Fig. 1. The exact shape of the curves, especially curve $B$, is unknown, i.e. curve $B$ need not be normal. Curve $A$ is for the gradualism model and curve $B$ is for the punctuated equilibrium model.

While the new curves of Fig. 3A and B are more reasonable for morphological data sets, the curves are not qualitatively different, and basically both look like the curve we obtained for 110 species of bats, Fig. 2C.

These two theoretical curves cannot be distinguished from each other because the placement of the punctuated equilibrium curve to the right of the gradualism curve (as in Fig. 3) assumes large morphological changes at speciation. But, punctuated equilibrium does not demand large morphological changes at speciation, only that most morphological changes occur at speciation. Therefore, the curve of the punctuated equilibrium model can be placed anywhere on the $\mathrm{X}$ axis and be of almost any shape, depending on the distribution of the morphological shifts at speciation within the taxon in question. At one extreme the curve might be shifted far to the right, on the other it could be identical to the gradualism model's predicted curve. Based on this logic, one can distinguish gradualism vs. punctuated equilibrium using neontological morphometric data only if the morphological shifts associated with speciation under punctuated equilibrium are large.

When looking at real data, we must know what a large morphological shift is in order to discern whether the distance to nearest neighbor 
is left or right shifted. The best way to start is to compare the morphological distances found within different levels of these taxonomic hierarchies. Both models predict more similarities among individuals within a population than among individuals belonging to different species. The question is, are there gaps between the intrapopulational, interpopulational, intrageneric and intergeneric distance curves? If the formation of higher taxonomic categories typically is the result of a few large morphological revolutions, then gaps are predicted. Our data indicate smooth transitions with large overlaps along these taxonomic hierarchies (Fig. 2). Large morphological shifts at speciation do not need to be invoked to explain the morphological patterns found up to the generic level for these bats. However, the curves of Fig. 2 could be produced by either gradualism or punctuated equilibrium by many normally small, morphological shifts occurring precisely at the speciation event.

\section{Conclusion}

We conclude that both the original model proposed by Ricklefs and our modifications of it are incapable of producing a conclusive test between gradualism and punctuated equilibrium. The data indicate that if punctuated equilibrium is operating, the morphological divergence at speciation must normally be small, hardly more than the level of intraspecific differences. This conclusion is based on the broad overlap and the relatively low variance of the curves in Fig. 2. Had gaps occurred between taxonomic hierarchies then large morphological revolutions would have to be invoked for the creation of new genera. This is not the case.

The single most important problem in our study is how to define nearest neighbors operationally. Ricklefs (1980) meant distance to nearest phylogenetic neighbor. But the true phylogenetic relationships among these species of bats are poorly known. One way around the problem is to base the nearest neighbor criterion on the morphology itself (Ricklefs, pers. comm.). The assumption is that little or no morphological convergence takes place. Future studies must find some independent means of discerning nearest phylogenetic neighbors. For now, we use morphology as a first approximation. The assumption of random speciation through time is also critical. Given that we are dealing with two world-wide families with species in a variety of habitats, it may well be that speciation has been random through time. However, if speciation events are clumped in time, then gradualism would produce very different predictions depending upon when these periods of rapid speciation occurred.

While problems exist in Ricklefs' model and our analysis, we wish to emphasize the importance of the kind of data presented here. Little is known about the structure of morphological space or the nature of morphologic gaps between species, genera, families, etc. Other groups may be quite different from bats, or other types of data may yield different results. Whatever the case, the data must be collected and analyzed to give evolutionary theoreticians some quantitative idea of the morphological structure of taxa.

\section{Acknowledgments}

We wish to thank J. W. Fitzpatrick, R. M. Timm and H. K. Voris for critically reading the manuscript. We also thank Sarah Derr Bruner for typing the manuscript.

\section{Literature Cited}

Eldredge, N. AND S. J. Gould. 1972. Punctuated equilibrium: an alternative to phyletic gradualism. Pp. 82-115. In: Schopf, T., ed. Models in Paleobiology. Freeman, Cooper; San Francisco.

FreEmaN, P. W. 1981. A multivariate study of the family Molossidae (Mammalia, Chiroptera): Morphology, ecology, evolution, Fieldiana, Zool. 7:1-173.

Lemen, C. A. 1981. The effectiveness of methods of shape analysis. Fieldiana-Zool. (in press)

Ricklefs, R. E. 1980. Phyletic gradualism vs. punctuated equilibrium: applicability of neontological data. Paleobiology. 6:271275 .

Stanley, S. M. 1979. Macroevolution: Pattern and Process. W H. Freeman; San Francisco.

\section{Appendix \\ Characters Used}

1. Head and body, length from tag or alcoholic specimen.

2. Tail, length from tag or alcoholic specimen.

3. Ear, length from tag or alcoholic specimen.

4. Hindfoot, length from heel to end of longest toenail on dry or wet specimen.

5. Tibia, length from knee joint at indentation between femur and tibia to distal end of tibia (not including tarsals).

6. Forearm, length from olecranon process to shallow notch proximal to thumb (including carpals)

7. Third metacarpal, length from distal endpoint of forearm to distal end of bone.

8. Third metacarpal first phalanx, greatest length of bone

9. Third metacarpal second phalanx and tip, length from proximal end of second phalanx to distal end of cartilaginous tip of wing (curve of tip measured in two straight lines breaking at greatest point in curve). This includes the third phalanx in molossids. Emballonurids have no such phalanx.

10. Fourth metacarpal, length from distal endpoint of forearm to distal process of bone.

11. Fourth metacarpal first phalanx, greatest length of bone. 
12. Fourth metacarpal second phalanx, greatest length of bone (no cartilage included).

13. Fifth metacarpal, length from distal endpoint of forearm to distal process of bone.

14. Fifth metacarpal first phalanx, greatest length of bone

15. Fifth metacarpal second phalanx, greatest length of bone plus cartilaginou tip.

16. Greatest skull length, from posteriormost part of occipital to anteriormost point of the premaxillary bone (taken on a line parallel to line connecting foramen magnum and anterior point on the premaxillary).

17. Palatal length, from posterior border of hard palate to anterior border of premaxillary bone.

18. Maxillary toothrow, length from anterior alveolar border of canine to posterior alveolar border of $\mathbf{M}^{3}$.

19. Upper molariform row, length from $\mathbf{P M}^{4}$ to $\mathbf{M}^{3}$ (alveolar).

20. Lacrimal width, width across rostrum dorsally at protruberances of greatest width near lacrimal canals.

21. Interorbital width, width across rostrum dorsally between lacrimals and least constriction, just anterior to postorbital process in emballonurids and analogous place in molossids.

22. Postorbital width, dorsal width at most constricted part of skull.

23. Zygomatic breadth, width taken across zygomatic arches at widest point.

24. Breadth at mastoids, greatest breadth at mastoid processes.

25. Breadth of braincase, breadth just dorsal to posterior juncture of zygomatic process.

26. Height of braincase, from basisphenoid and basioccipital bones to top of braincase on either side of sagittal crest.

27. Width at upper canines, width between lingual alveolar borders of uppe canines.
28. Width at upper molars, width between lingual alveolar borders of upper third molars.

29. Height of upper canine, greatest length from point immediately dorsal to cingulum to end of tooth

30. Length of $\mathbf{M}^{3}$, anterior-posterior length of tooth.

31. Width of $\mathbf{M}^{3}$, greatest lateral-medial width of tooth.

32. Dentary length, from midpoint of mandibular condyle to anteriormost point of dentary.

33. Condylocanine length, from midpoint of condyle to anterior border of alveolus of lower canine.

34. Condyle to $M_{1}$, length from midpoint of condyle to anterior face of protoconid of first lower molar.

35. Lower toothrow, length from posterior alveolar border of $\mathbf{M}_{3}$ to anterior alveolar border of $\mathrm{C}_{1}$.

36. Moment arm of temporal, length from midpoint of condyle to tip of coronoid process.

37. Moment arm of masseter, length from midpoint of condyle to tip of angular process.

38. Height of coronoid, from indentation of ventral mandibular border to tip of coronoid.

39. Dentary thickness, width of dentary at base of protoconid of $\mathbf{M}_{2}$ taken on the lateral surface (calipers must be braced).

40. Height of condyle above toothrow, horizontal crosshair in scope aligned with valleys at the bases of hypoconid and protoconid of $M_{1}$ and $M_{3}$ (these have less wear than the tops of the cusps). Height taken from this line to top of condyle with braced calipers.

41. Height of lower canine, greatest length from point immediately ventral to cingulum to top of tooth.

42. Length of condyle, longitudinal length of mandibular condyle. 